\title{
Hippocampal Volume in Type 1 Diabetes
}

\author{
Michael Murray, ${ }^{1}$ Molly Stanley, ${ }^{2}$ Heather M Lugar $^{3}$ and Tamara Hershey ${ }^{4}$
}

1. Undergraduate Researcher, Department of Psychiatry; 2. PhD Candidate, Department of Neurology; 3. Image Analyst, Department of Psychiatry; 4. Professor, Departments of Psychiatry, Neurology and Radiology, Washington University School of Medicine, St Louis, Missouri, us

\begin{abstract}
The hippocampus plays an important role in human memory and is known to be vulnerable to extreme hyperglycaemia and hypoglycaemia in animal models of type 1 diabetes. Within humans with type 1 diabetes, exposure to glycaemic extremes has been associated with alterations in hippocampal structure and in memory function, but results are inconsistent. It has been hypothesised that the effects of hypoglycaemia and hyperglycaemia on the hippocampus may depend on when during neurodevelopment these extremes occur, possibly explaining some of these inconsistencies. However, data addressing this concept are limited. We review here the existing literature on this complex topic and suggest future avenues of required research.
\end{abstract}

\section{Keywords}

Hippocampus, diabetes, hypoglycaemia, hyperglycaemia, development, brain

Disclosure: The authors have no conflicts of interest to declare.

Acknowledgements: The authors gratefully acknowledge the following support from the National Institutes of Health (NIH) DK064832 (Hershey) and from the National Science Foundation (NSF) DGE-1143954 (Stanley).

Received: 5 September 2013 Accepted: 12 November 2013 Citation: European Endocrinology, 2014;10(1):14-7 DOI:10.17925/EE.2014.10.01.14

Correspondence: Tamara Hershey, Washington University School of Medicine, Campus Box 8225, 660 South Euclid Avenue, St Louis, MO 63110, US. E: tammy@wustl.edu

The hippocampus plays an important role in human learning and memory and is known to be vulnerable to the effects of stress and disease. ${ }^{1}$ Within animal models of type 1 diabetes, ${ }^{2}$ significant hyperglycaemia and hypoglycaemia exposure has been shown to cause complex molecular and structural changes in the hippocampus. ${ }^{2,3}$ Within humans with type 1 diabetes, exposure to both extremes of the glycaemic spectrum have been inconsistently associated with alterations in hippocampal structure ${ }^{4-9}$ and worse memory function, ${ }^{8-11}$ but it is unclear whether these two findings relate to each other. Given that the diagnosis of type 1 diabetes and exposure to glycaemic extremes often occur at a time of dynamic neurodevelopment, it has been hypothesised that exposure at early ages may have different effects on the brain than exposure in adulthood, which could explain some of these inconsistent findings. However, data addressing this concept are limited. In this article, we review the existing literature on the effects of hyperglycaemia and hypoglycaemia in type 1 diabetes, with focus on the structure and function of the hippocampus during both development and adulthood.

\section{Hippocampal Structure, Volume and Function}

The hippocampus is a subcortical, primarily grey matter structure residing bilaterally within the medial temporal lobes. It consists of several regions, including the cornu ammonis (CA) and its subregions (CA1-CA4), the dentate gyrus (DG) and the subiculum, which connects the hippocampus to the parahippocampal gyrus. ${ }^{1}$ These regions contain intra- and interhippocampal connections through multiple synaptic pathways ${ }^{12}$ and have been ascribed specialised roles in the processing of information. ${ }^{13-16}$ Overall, the hippocampus appears to play an important role in laying down and consciously retrieving explicitly learned, novel information. ${ }^{17}$ Within this complex process, the CA1 has been selectively associated with long-term and autobiographical memory, ${ }^{15,18}$ the CA2 and CA3 with encoding processes and the DG with early retrieval and episodic memory formation. ${ }^{15,19}$

The hippocampus develops heterogeneously and nonlinearly up to age $25^{20,21}$ and is a site of sustained neurogenesis throughout the lifespan. ${ }^{20-22}$ Hippocampal volume is developmentally dynamic, with the posterior and anterior portions increasing and decreasing respectively with age. ${ }^{20}$ The total volume steeply increases until approximately age 4 , followed by a gradual increase and reaching a peak in volume around age 10.21 Hippocampal volume remains fairly stable until age 50 in healthy adults, followed by a variable level of decline and a significant decrease in volume by age $80 .{ }^{23}$ The relationship between developmental changes in hippocampal volume and memory function is complex and still unclear. A meta-analysis of the literature examining hippocampal volume and memory performance in healthy children, adolescents and young adults revealed that smaller hippocampal volume was associated with better memory performance and that this effect could reflect sufficient developmental pruning leading to overall lower volume. ${ }^{24}$ In healthy adults, the associations are less clear as both larger ${ }^{25-28}$ and smaller29,30 volumes have been associated with better explicit memory performance. The dynamic development of the hippocampus could lead to age-selective vulnerability and differential outcomes in patient populations. In adult onset disease states, such as Alzheimer's disease, smaller volumes are typically related to worse performance. ${ }^{31,32}$ However, in developmental injury populations, such as prenatal drug exposure, larger volumes have been related to worse performance..$^{33}$ Additionally, adults with early (diagnosed anytime before age 50) and late onset depression have reduced hippocampal volume and memory impairment compared with controls, but those with 
Table 1: Studies Examining Hippocampal Structure in Type 1 Diabetes

\begin{tabular}{|c|c|c|c|c|c|c|}
\hline Study & Groups: Number & $\begin{array}{l}\text { Age } \\
\text { (Years) }\end{array}$ & $\begin{array}{l}\text { Structural } \\
\text { Measure }\end{array}$ & $\begin{array}{l}\text { Type } 1 \text { Diabetes } \\
\text { versus Controls }\end{array}$ & $\begin{array}{l}\text { Effects of } \\
\text { Hypoglycaemia }\end{array}$ & $\begin{array}{l}\text { Effects of } \\
\text { Hyperglycaemia }\end{array}$ \\
\hline $\begin{array}{l}\text { Lobnig et al., } \\
2005^{7}\end{array}$ & $\begin{array}{l}\text { Type } 1 \text { diabetes: } 13 \\
\text { Controls: } 13\end{array}$ & $35-48$ & Hippocampal volume & No differences & No relationship & No relationship to $\mathrm{HbA}_{1 \mathrm{c}}$ \\
\hline $\begin{array}{l}\text { Hershey et al., } \\
2010^{4}\end{array}$ & $\begin{array}{l}\text { Type } 1 \text { diabetes: } 95 \\
\text { Controls: } 49\end{array}$ & $7-17$ & Hippocampal volume & No differences & $\begin{array}{l}\text { More severe episodes } \\
\text { related to larger volume }\end{array}$ & $\begin{array}{l}\text { No relationship to } \\
\text { weighted } \mathrm{HbA}_{1 \mathrm{c}}\end{array}$ \\
\hline $\begin{array}{l}\text { Aye et al., } \\
2011^{5}\end{array}$ & $\begin{array}{l}\text { Type } 1 \text { diabetes: } 27 \\
\text { Controls: } 18\end{array}$ & $3-10$ & Hippocampal volume & $\begin{array}{l}\text { Controls: positive } \\
\text { correlation with age } \\
\text { Type } 1 \text { diabetes: } \\
\text { no correlation }\end{array}$ & No relationship & $\begin{array}{l}\text { No relationship to } \\
\text { weighted } \mathrm{HbA}_{1 \mathrm{c}}\end{array}$ \\
\hline $\begin{array}{l}\text { Ho et al., } \\
2008^{56}\end{array}$ & $\begin{array}{l}\text { Type } 1 \text { diabetes } \\
\text { seizures: } 31 \\
\text { Type } 1 \text { diabetes no } \\
\text { seizures: } 29\end{array}$ & $\begin{array}{l}10.2 \text { (average) } \\
9.8 \text { (average) }\end{array}$ & Hippocampal volume & No control group & No relationship & Not examined \\
\hline $\begin{array}{l}\text { Antenor-Dorsey } \\
\text { et al., } 2013^{6}\end{array}$ & $\begin{array}{l}\text { Type } 1 \text { diabetes: } 73 \\
\text { Controls: } 30\end{array}$ & $9-22$ & $\begin{array}{l}\text { White matter } \\
\text { radial diffusivity }\end{array}$ & No differences & No relationship & $\begin{array}{l}\text { Increased diffusivity } \\
\text { with more } \\
\text { hyperglycaemic events }\end{array}$ \\
\hline
\end{tabular}

$\mathrm{HbA}_{1 \mathrm{c}}=$ glycated haemoglobin.

adult onset are more severely affected than those with earlier onset, ${ }^{34}$ suggesting that the effects of pathology are also dependent on the stage of development. Hippocampal volumes have been reported to be smaller than controls in adults with schizophrenia, ${ }^{35,36}$ adult onset epilepsy, ${ }^{37,38}$ Alzheimer's disease ${ }^{39-41}$ and in both adult ${ }^{42,43}$ and adolescent onset depression. ${ }^{44}$ Elevated levels of stress hormones, common in many neuropsychiatric disorders, such as depression, have been associated with smaller hippocampal volume in adults. ${ }^{45}$ The explanation for hippocampal atrophy from chronic exposure to these hormones appears to be loss of dendrites and synapses within the hippocampus. ${ }^{46}$ However, larger volumes have been reported in certain developmental disorders including fragile $\mathrm{X}$ syndrome, ${ }^{47}$ autism ${ }^{48}$ and attention-deficit hyperactivity disorder. ${ }^{49}$ The reasons for hippocampal enlargement are less clear, but a mouse model of fragile $X$ syndrome suggests that longer, immature dendritic spines on hippocampal neurons and reduced pruning could lead to excess volume..$^{50}$ Adult subjects with posttraumatic stress disorder (PTSD) have smaller hippocampal volumes ${ }^{51,52}$ yet youth and adolescents with PTSD have larger hippocampal volumes compared with controls. ${ }^{53}$ None of these volumetric differences have been compared with hippocampus-dependent memory performance, leaving the correlation between volume and function in different patient populations still uncertain. Clearly, hippocampal volume is differentially affected by the stage of development in which the pathology occurs. These complex, developmental patterns in the hippocampus are highly relevant to the study of type 1 diabetes, as this disorder is typically diagnosed in childhood and has an impact on blood glucose levels that continues throughout development.

\section{Hippocampal Structure, Volume and Function in Type 1 Diabetes}

The brain relies on a consistent supply of glucose for proper function. Individuals with type 1 diabetes experience both hyperglycaemia from disrupted insulin production and hypoglycaemic episodes as a complication of insulin treatment. Animal studies have demonstrated that hyperglycaemia can affect cell number and anatomy in the hippocampus ${ }^{2,54}$ and hypoglycaemia causes neuronal death, particularly in the DG and CA1 regions. ${ }^{3}$ Case reports suggest that adults with type 1 diabetes who experienced profound hypoglycaemic episodes can result in hippocampal lesions or smaller hippocampal volumes accompanied by cognitive deficits including anterograde amnesia, which is the selective inability to encode new information for later conscious recall.,.9 Severe hypoglycaemia can lead to cell death due to an excess release of excitatory neurotransmitter. Due to a high concentration of excitatory neurotransmitter receptors in the hippocampus, this excitotoxic cascade quickly leads to neuronal necrosis ${ }^{55}$ and without the ability to overcome this cell loss, a reduction in overall volume could result.

Based on these animal studies and case reports, larger group studies have looked for macrostructural differences in the hippocampus of the general type 1 diabetes population, and asked whether hippocampal volumes are related to exposure to glycaemic extremes (see Table 1). Lobnig et al. ${ }^{7}$ examined a small sample of adults with type 1 diabetes and found mild cerebral atrophy and evidence of impaired cognitive performance compared with age- and gender-matched controls, but no differences in hippocampal volume or memory function. Within the type 1 diabetes group, only three individuals had severe hypoglycaemic episodes in the past, which significantly limited the power of analyses to detect any potential relationships with hypoglycaemia exposure. To our knowledge, no other currently published studies have examined hippocampal volume in adults with type 1 diabetes. To understand the long-term effects of diabetic complications on hippocampal development and function, it will be important to have larger and more varied exposures to hypoglycaemia in future studies.

Since type 1 diabetes typically has a childhood onset and some extreme glycaemic states occur more frequently in childhood (e.g. severe hyperglycaemia onset, severe hypoglycaemia), more recent studies have focused on examining the hippocampus in youth with type 1 diabetes (see Figure 1). Hershey et al. ${ }^{4}$ examined a large sample of youth with type 1 diabetes and compared them with their siblings without diabetes. No between-group differences were found, but hippocampal grey matter volume was larger in those children with type 1 diabetes who experienced three or more severe hypoglycaemic episodes in the past compared with all other type 1 diabetes subgroups or controls. This effect was not explained by hyperglycaemia exposure, age of onset of type 1 diabetes, age or gender. In a younger and smaller sample, Aye et al. ${ }^{5}$ found no significant differences between the type 1 diabetes and control groups, or between type 1 subjects with diabetes with and without hypoglycaemiarelated seizures in hippocampal volume. However, this study did report a positive correlation between hippocampal volume and age in the control 


\section{Figure 1: Automated Segmentation of the Hippocampus in a Healthy 18-year-old Male using Freesurfer, a Neuroimaging Method used to Measure Hippocampal Volume}

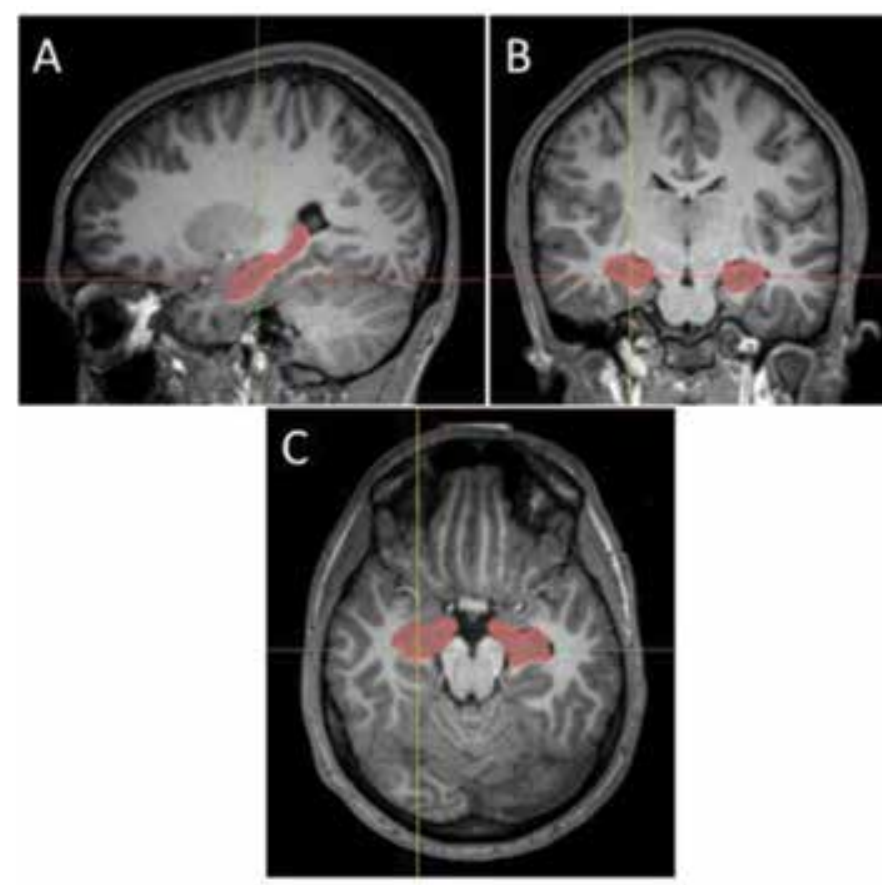

The hippocampus is shown (in red) in A) sagittal, B) coronal, and C) transverse orientations, with crosshairs placed on the left hippocampus. (Image generated using authors' own dataset).

group that was not present in children with type 1 diabetes, suggesting altered hippocampal development in these patients. An additional study by Ho et al. ${ }^{56}$ found no differences in hippocampal volume between youth with type 1 diabetes who had experienced hypoglycaemia-related seizures compared with those who had not. A healthy control group was not included for comparison.

It is unknown how severe hypoglycaemia in type 1 diabetes could lead to an enlarged hippocampus in children, but speculation can be made based on the current literature. In animal studies, knocking out a presynaptic scaffolding protein can result in a significantly larger hippocampus. ${ }^{57}$ While this presynaptic protein may not be relevant to hypoglycaemia, this study did find that the enlarged volume was due to uncontrolled neurogenesis and gliosis, seen by an increase in the number of both neurons and glia, as well as reduced cell death and an increase in brain-derived neurotrophic factor (BDNF). ${ }^{57}$ Brain insults, such as severe hypoglycaemia, have been shown to increase expression of BDNF and other growth factors, ${ }^{58}$ likely as a compensatory mechanism, and levels of these neurotrophic factors fluctuate throughout development with neurogenesis and are particularly high in the hippocampus. ${ }^{59}$ Moderate, chronic overexpression of BDNF leads to longer, more complex dendrites in hippocampal granule neurons ${ }^{60}$ that could lead to excess volume without sufficient pruning. Reactive gliosis, neurogenesis, insufficient pruning and compensatory responses to hypoglycaemia could all be involved in hippocampal enlargement and will only be determined by further mechanistic experiments using animal models of diabetes and hypoglycaemia. Notably, no relationship was found between measures of hyperglycaemia exposure and hippocampal volumes in three of these studies. ${ }^{45,7}$ By contrast, AntenorDorsey et al. ${ }^{6}$ recently used diffusion tensor imaging (DTI) to examine white matter microstructural integrity in adolescents with type 1 diabetes and found that greater exposure to severe hyperglycaemic episodes (most involving documented diabetic ketoacidosis) was associated with increased radial diffusivity in the hippocampus, suggesting that anatomical differences other than overall volume could be present in children with type 1 diabetes. Thus, within children with type 1 diabetes, extreme glycaemic exposure in the form of severe hypoglycaemia or severe hyperglycaemia may have a greater impact on the macrostructure of the hippocampus than lower level, chronic exposure. This pattern is in contrast to adults and adolescents with chronic low level hyperglycaemia from type 2 diabetes, and no severe glycaemic exposure, who tend to have smaller hippocampal volumes compared with controls. ${ }^{61,62}$ In adults with type 2 diabetes, glycated haemoglobin $\left(\mathrm{HbA}_{1 \mathrm{c}}\right)$ levels have been negatively correlated with hippocampal volume; 63 however, in an adolescent population, these two factors were not associated which may indicate agedependent effects from chronic exposure to hyperglycaemia on the hippocampus. ${ }^{62}$ Animal models suggest that chronic hyperglycaemia can reduce the complexity of neuronal dendrites and dendritic spines ${ }^{54}$ and damaging these neuronal processes could lead to a smaller hippocampal volume, ${ }^{46}$ but developing adolescents might be able to overcome this loss due to the presence of growth factors or other developmentally regulated molecules.

Although type 1 diabetes and exposure to glycaemic extremes does not appear to have striking macrostructural effects on the hippocampus in the current human literature, it is possible that hippocampal function could still be compromised. In animals, hyperglycaemia is associated with impairment in explicit memory function. ${ }^{64}$ Limited neuroimaging studies have examined hippocampus-dependent memory tasks in patients with type 1 diabetes, but one functional magnetic resonance imaging (fMRI) study found that acute hypoglycaemia is associated with higher brain activation in the hippocampus and other brain areas during working memory tasks, suggesting a decrease in cerebral efficiency, although this was not examined in hippocampus-mediated explicit memory tasks. ${ }^{11}$ Additionally, in humans, severe hypoglycaemic episodes are associated with decreased long-term spatial memory; effects are largest when the severe hypoglycaemic episodes were experienced before age five. ${ }^{10}$ This finding supports the concept that the hippocampus may be differentially vulnerable depending on the developmental stage at which hypoglycaemia occurs. This possibility is also supported by the finding that adult rats show more hypoglycaemic cell death in the hippocampus than the young, ${ }^{65}$ but in young rats, long-term potentiation (a presumed mechanism of learning and memory) is severely decreased in the hippocampus with hypoglycaemia. ${ }^{66}$

\section{Conclusions}

The hippocampus is an important, complex structure that develops heterogeneously, making it difficult to differentiate the effects of altered glycaemic states in childhood on its structure and function. Overall, both hypoglycaemic and hyperglycaemic episodes have been correlated with structural changes in the hippocampus, ${ }^{4,6}$ but how these changes relate to memory function is still unclear. Correlations between hippocampal volume and cognitive performance in youth and adults with type 1 diabetes will be necessary and are currently under way. Future crosssectional studies should continue to include healthy controls and also examine differences within type 1 diabetes based on extreme glycaemic exposure at both ends of the spectrum. The age of type 1 diabetes onset and age at which severe glycaemic extremes occur also should be considered when examining both hippocampal volumes and 
memory function in children and adults. Whether structural differences in the hippocampus of children can be overcome with continued development is unknown but it is an important question to address in future, longitudinal experiments. Finally, it is important to mention that glucose is not the only substrate dysregulated in type 1 diabetes that could affect hippocampal volume and function. Insulin also varies significantly in type 1 diabetes patients and the hippocampus has a high density of insulin receptors that can affect memory. ${ }^{67}$ Continued work in this area is crucial to increase our understanding of the complex interplay between hippocampal development, volume and function and the fluctuating metabolic status of individuals with type 1 diabetes. Ultimately, this work will improve our ability to predict the neurobiological and functional risks that these individuals face, providing a rational basis for evaluation, prevention and treatment.
1. Andersen P, Morri, R, Amaral, D, et al., The Hippocampus Book, New York, US: Oxford University Press, 2006

2. Malone, Jl, Hanna SK, Saporta S, Hyperglycemic brain injury in the rat, Brain Res, 2008:1076:9-15.

3. Auer RN, Wieloch T, Olsson Y, Siesjö BK, The distribution of hypoglycemic brain damage, Acta Neuropathol, 1984:64:177-91.

4. Hershey T, Perantie DC, Wu J, et al., Hippocampal volumes in youth with type 1 diabetes, Diabetes, 2010;59:236-41.

5. Aye T, Reiss AL, Kesler S, et al., The feasibility of detecting neuropsychologic and neuroanatomic effects of type 1 diabetes in young children, Diabetes Care, 2011;34:1458-62.

6. Antenor-Dorsey JA, Meyer E, Rutlin J, et al., White matter microstructural integrity in youth with type 1 diabetes, Diabetes, 2013;62:581-9.

7. Lobnig BM, Krömeke O, Optenhostert-Porst C, Wolf OT, Hippocampal volume and cognitive performance in long standing Type 1 diabetic patients without macrovascular complications, Diabet Med, 2005:23:32-9.

8. Kirchhoff BA, Lugar HM, Smith SE, et al., Hypoglycaemiainduced changes in regional brain volume and memory function, Diabet Med, 2013;30:e151-6.

9. Holemans X, Dupuis M, Misson N, Vanderijst JF, Reversible amnesia in a Type 1 diabetic patient and bilateral hippocamp lesions on magnetic resonance imaging (MRI), Diabet Med, 2001;18:761-3.

10. Perantie DC, Lim A, Wu J, et al., Effects of prior hypoglycemia and hyperglycemia on cognition in children with type 1 diabetes mellitus, Pediatr Diabetes, 2008:9:87-95.

11. Bolo NR, Musen G, Jacobson AM, et al., Brain activation during working memory is altered in patients with type 1 diabetes during hypoglycemia, Diabetes, 2011;60:3256-64.

12. Duvernoy HM, The Human Hippocampus: An Atlas of Applied Anatomy, Munich, Germany: JF Bergmann-Verlag, 1988.

3. Lee I, Rao G, Knierim JJ, A double dissociation between hippocampal subfields: differential time course of CA3 and CA1 place cells for processing changed environments, Neuron, 2004;42:803-15.

14. Hartley M, Taylor N, Taylor J, Subfield variations in hippocampa processing-components of a spatial navigation system, Neura Netw, 2005;18:611-19.

15. Mueller SG, Chao LL, Berman B, Weiner MW, Evidence for functional specialization of hippocampal subfields detected by MR subfield volulmetry on high resolution images at $4 \mathrm{~T}$, Neuroimage, 2012;56:851-7.

16. Vazdarjanova A, Guzowski JF, Differences in hippocampal neuronal population responses to modifications of an environmental context: evidence for distinct, yet complementary, functions of CA3 and CA1 ensembles, Neurosci, 2004;24:6489-96.

17. Squire LR, Memory and the hippocampus: a synthesis from findings with rats, monkeys, and humans, Psychol Rev 1992;99:195-231.

18. Bartsch T, Döhring J, Rohr A, et al., CA1 neurons in the human hippocampus are critical for autobiographical memory, mental time travel, and autonoetic consciousness, Proc Natl Acad Sci U S A, 2011:108:17562-7.

19. Eldridge LL, Engel S, Zeineh MM, et al., A dissociation of encoding and retrieval processes in the human hippocampus, Neurosci, 2005:25:3280-6.

20. Gogtay N, Nugent III TF, Herman DH, et al. Dynamic mapping of normal human hippocampal development, Hippocampus, 2006;16:664-72

21. Uematsu A, Matsui M, Tanaka C, et al., Developmental trajectories of amygdala and hippocampus from infancy to early adulthood in healthy individuals, Plos One, 2012; $7:$ : 46970

22. Eriksson PS, Perfilieva E, Bjork-Eriksson T, et al., Neurogenesis in the adult human hippocampus, Nat Med, 1998;4:1313-7.

23. Scahill RI, Frost $C$, Jenkins $R$, et al., A longitudinal study of

brain volume changes in normal aging using serial registered

magnetic resonance imaging, Arch Neurol, 2003;60:989-94.
24. Van Petten C, Relationship between hippocampal volume and memory ability in healthy individuals across the lifespan: review and meta-analysis, Neuropsychologia, 2004:42:394-413.

25. Pohlack ST, Meyer P, Cacciaglia R, et al., Bigger is better! Hippocampal volume and declarative memory performance in healthy young men, Brain Struct Funct, 2014;219(1):255-67.

26. Schinazi VR, Nardi D, Newcombe NS, et al., Hippocampal size predicts rapid learning of a cognitive map in humans, Hippocampus, 2013;23:515-28.

27. Driscoll I, Hamilton DA, Petropoulos $\mathrm{H}$, et al., The aging hippocampus: cognitive, biochemical and structural findings, Cereb Cortex, 2003;13:1344-51

28. Engvig A, Fjell AM, Westlye LT, et al., Hippocampal subfield volumes correlate with memory training benefit in subjective memory impairment, Neurolmage, 2012;61:188-94.

29. Chantôme M, Perruchet P, Hasboun D, et al., Is there a negative correlation between explicit memory and a negative correlation between explicit memory and

30. Van Petten C, Plante E, Davidson, PSR, et al., Memory and executive function in older adults: relationships with tempora and prefrontal gray matter volumes and white matter hyperintensities, Neuropsychologia, 2004;42:1313-35. 31. Foster JK, Meikle A, Goodson G, et al., The hippocampus and delayed recall: bigger is not necessarily better?, Memory, 1999;7:715-32.

32. Köhler S, Black SE, Sinden M, et al., Memory impairments associated with hippocampal versus parahippocampal-gyrus atrophy: an MR volumetry study in Alzheimer's disease, Neuropsychologia, 1998:36:901-14.

33. Riggins T, Cacic K, Buckingham-Howes S, et al., Memory abilit/ and hippocampal volume in adolescents with prenatal drug exposure, Neurotoxicol Teratol, 2012:34:434-41.

34. Hickie I, Naismith S, Ward PB, et al., Reduced hippocampa volumes and memory loss in patients with early- and lateonset depression, Br J Psychiatry, 2005;186:197-202.

35. Nelson MD, Saykin AJ, Flashman LA, Riordan HJ, Hippocampa volume reduction in schizophrenia as assessed by magnetic resonance imaging: a meta-analytic study, Arch Gen Psychiatry, 1998;55:433-40.

36. Velakoulis D, Stuart GW, Wood SJ, et al., Selective bilateral hippocampal volume loss in chronic schizophrenia, Biol Psychiatry, 2011:50:531-9.

37. Barr WB, Ashtari M, Schaul N, Bilateral reductions in hippocampal volume in adults with epilepsy and a history of febrile seizures, I Neurol Neurosurg Psychiatry, 1997:63:461-7.

38. Briellmann RS, Berkovic SF, King MA, Jackson GD, Seizureassociated hippocampal volume loss: a longitudinal magnetic resonance study of temporal lobe epilepsy, Ann Neurol, 2002;51:641-4.

39. Jack CR, Petersen RC, Xu Y, et al., Rates of hippocampal atrophy correlate with change in clinical status in aging and AD, Neurology, 2000;55:484-90.

40. Vijayakumar A, Vijayakumar A, Comparison of hippocampal volume in dementia subtypes, ISRN Radiology, Volume 2013 (2013), Article ID 174524, 5 pages.

41. Gosche KM, Mortimer JA, Smith CD, et al., Hippocampal volume as an index of Alzheimer neuropathology: findings from the Nun Study Neurology, 2002:58:1476-82.

42. Bremner JD, Narayan M, Anderson ER, et al., Hippocampal volume reduction in major depression, Am J Psychiatry, 2000:157:115-7.

43. Sheline $Y$, Gado $M$, Kraemer $H$, Untreated depression and hippocampal volume loss, Am J Psychiatry, 2003;160:1516-8.

44. MacMaster FP, Kusumakar V, Hippocampal volume in early onset depression, BMC Med, 2004;2:2.

45. Lupien SJ, de Leon M, de Santi S, et al., Cortisol levels during human aging predict hippocampal atrophy and memory deficits, Nat Neurosci, 1998;1:69-73.

46. Tata DA, Anderson BJ, The effects of chronic glucocorticoid exposure on dendritic length, synapse numbers and glia volume in animal models: Implications for hippocampal volume reductions in depression, Physiol Behav 2010;99:186-93.

47. Reiss AL, Lee J, Freund L, Neuroanatomy of fragile X syndrome: the temporal lobe, Neurology, 1994:44:1317-24.

48. Schumann CM, Hamstra J, Goodlin-Jones BL, et al., The amygdala is enlarged in children but not adolescents with autism; the hippocampus is enlarged at all ages, J Neurosci, 2004:24:6392-401.

49. Plessen KJ, Bansal R, Zhu H, et al., Hippocampus and amygdala morphology in attention-deficit/hyperactivity disorder, Arch Gen Psychiatry, 2006;63:795-807.

50. Grossman AW, Elisseou NM, McKinney BC, Greenough WT, Hippocampal pyramidal cells in adult Fmr1 knockout mice exhibit an immature-appearing profile of dendritic spines, Brain Res, 2006;1084:158-64.

51. Gurvits TV, Shenton ME, Hokama H, et al., Magnetic resonance imaging study of hippocampal volume in chronic, combatrelated posttraumatic stress disorder, Biol Psychiatry. related posttraum

52. Bremner JD, Randall P, Vermetten E, et al., Magnetic resonance imaging-based measurement of hippocampal volume in posttraumatic stress disorder related to childhood physical and sexual abuse-a preliminary report, Biol Psychiatry, 1997;41:23-32.

53. Tupler LA, De Bellis MD, Segmented hippocampal volume in children and adolescents with posttraumatic stress disorder, Biol Psychiatry, 2006;59:523-9.

54. Malone II, Hanna S, Saporta S, et al., Hyperglycemia not hypoglycemia alters neuronal dendrites and impairs spatial memory Pediatr Diabetes, 2008:9:531-9.

55. Auer RN, Hypogycemic brain damage, Forensic Sci Int 2004:146:105-10.

56. Ho MS, Weller NJ, Ives FJ, et al., Prevalence of structural central nervous system abnormalities in early-onset type 1 diabetes mellitus, J Pediatr, 2008;153:385-90.

57. Heyden A, Ionescu M-C S, Romorini S, et al., Hippocampa enlargement in Bassoon-mutant mice is associated with enhanced neurogeneis, reduced apoptosis, and abnormal BDNF levels, Cell Tissue Res, 2011;346:11-26.

58. Lindvall O, Ernfors P, Bengzon J, et al., Differential regulation of mRNAs for nerve growth factor, brain-derived neurotrophic factor, and neurotrophin 3 in the adult rat brain following cerebral ischemia and hypoglycemic coma, Proc Natl Acad SC U S A, 1992:89:648-52

59. Maisonpierre PC, Belluscio L, Friedman B, et al., NT-3, BDNF, and NGF in the developing rat nervous system: Parallel as well as reciprocal patterns of expression, Neuron, 1990;5:501-9.

60. Tolwani RJ, Buckmaster PS, varma S, et al., BDNF overexpression increases dendritic complexity in hippocampa dendtate gyrus, Neuroscience, 2002;114:795-805.

61. den Heijer T, Vermeer SE, van Dijk EJ, et al., Type 2 diabetes and atrophy of medial temporal lobe structures on brain MRI, Diabetologia, 2003;46:1604-10

62. Bruehl H, Sweat V, Tirsi A, et al., Obese adolescents with type 2 diabetes mellitus have hippocampal and frontal lobe volume reductions, Neurosci Med, 2011;2:34-42.

63. Bruehl $\mathrm{H}$, Wolf OT, Convit A, A blunted cortisol awakening response and hippocampal atrophy in type 2 diabetes mellitus, Psychoneuroendocrinology, 2009:34:815-21.

64. Stranahan AM, Arumugam TV, Cutler RG, et al., Diabetes impairs hippocampal function via glucocorticoid-mediated effects on new and mature neurons, Nat Neurosci, 2008;11:309-17.

65. Ennis K, Tran P, Seaquist ER, Rao R, Postnatal age influences hypoglycemia-induced neuronal injury in the rat brain, Brain Res, 2008;1224:119-26.

66. Yamada KA, Rensing N, Izumi Y, et al., Repetitive hypoglycemia in young rats impairs hippocampal long-term potentiation, Pediatr Res, 2004:55:372-9.

67. Zhao WQ, Chen H, Quon MJ, Alkon DL, Insulin and the insulin receptor in experimental models of learning and memory, Eur J Pharmacol, 2004;490:71-81. 